\title{
Into the minds of coffee consumers: perception, preference, and impact of information in the sensory analysis of specialty coffee
}

\author{
Ana Paula Pereira BRESSANI ${ }^{1}$, Silvia Juliana MARTINEZ ${ }^{2}$, Nádia Nara BATISTA², João Batista Pavesi SIMÃO², \\ Rosane Freitas SCHWAN ${ }^{2 *}$ (D)
}

\begin{abstract}
This study aimed to analyze the knowledge, perspectives, and preferences of consumers about specialty coffees and to investigate how information can influence the perception of taste and the sensory characteristics of consumers. A descriptive-analytic survey was conducted through a questionnaire in a digital format with 1005 respondents. Four trained Q-Grader tasters evaluated a sample of cherry coffee fermented. The Specialty Coffee Association developed the cupping protocol used. According to the perceived descriptors, a sensory analysis was performed with the same coffee with 101 consumers to evaluate the influence of information received before the analysis. The chocolate flavor is the most expected in coffee. However, the participants are willing to try different specialty coffees. The coffee has been considered excellent ( 85.15 points) by Q-Grader tasters and widely accepted by consumers. Check-all-that-Apply (CATA) test showed that consumers could be influenced by information. When the coffee has been presented without information, the consumers noticed a more caramel flavor. However, when the information has been added to the same coffee, the citric flavor was more noticeable. In conclusion, information on specialty coffees should be more widespread. Consumer's expectations can be influenced by information, which in turn can modify their sensory perception.
\end{abstract}

Keywords: coffee consumers; the influence of information; specialty coffee; CATA; fermented coffee.

Practical Application: Consumers' knowledge about specialty coffees helps the market to understand and to serve them assertively.

\section{Introduction}

Coffee is one of the most popular beverages in the world, and changes in production, processing, trading, appreciation, and the culture of consumers are noticeable (Guimarães et al., 2019). Specialty and high-quality coffees are gaining space in the market, meeting the demands of consumers (Giacalone et al., 2019; Ufer et al., 2019). The worldwide consumption of specialty coffee is growing (with an increase of 1.5\%), and this growth in the market is affected by new products, research, and specialized coffee shops (Guimarães et al., 2019). For these reasons, it is necessary to evaluate consumers' behavior and desires (Wang \& Yu, 2016), detecting a large number of markets that can be explored with greater accuracy and quality.

Market surveys are essential for understanding consumer intentions. The use of the internet (twitter, e-mail, among others) in the application of questionnaires using different qualitative sensory methods (such as completion task) has become very important to discover the motivations, perceptions, and attitudes of consumers about a product (Sass et al., 2020; Torres et al., 2020). However, there is not enough information about the specialty coffee market, especially about the characteristics and buying behavior of consumers (Guimarães et al., 2019).

Several studies have shown that extrinsic factors, such as packaging, brand, information, emotion, and atmospheric,

influence the sensory perception of food products (Spence, 2015; Li et al., 2019; Samoggia \& Riedel, 2019; Spence \& Carvalho, 2020). Acceptance testing (e.g., hedonic scale) and descriptive analysis are commonly used in the sensory analysis (Wang \& Yu, 2016). Although the DQA method and Focus Group are techniques that generate robust data, they are considered laborious, expensive, and demand highly trained tasters. Therefore, innovative methods using untrained tasters [such as Preferred Attribute Elicitation (PAE), Temporal Dominance Sensation (TDS), and Free Listing Task] are being studied and use as a replacement (Costa et al., 2020; Schuch et al., 2019; Silva et al., 2018; Vieira et al., 2020). Thus, different sensory methodologies can be used to select specific markets and then undergo specific, targeted marketing techniques (Carvalho et al., 2015).

Objective and subjective sensory information can have a positive impact on consumer preference (Giacalone et al., 2016; Wang \& Yu, 2016; Li et al., 2019; Sales et al., 2020). In particular, the Check-all-that-Apply (CATA) methodology has been widely used and is considered efficient for describing and discriminating between products by consumers. In this way, CATA responses are directly linked to consumers' perception of the product's characteristics, maximizing and complementing product acceptance results (Alcantara \& Freitas-Sá, 2018). 
This study aimed to analyze the knowledge and perspectives of consumers about coffees (commodity, specialty, and fermented), measure the acceptance of a specialty coffee, and investigate how information can influence the sensory experience of consumers.

\section{Materials and methods}

\subsection{Consumer knowledge of commodity, specialty, and fermented coffees}

A descriptive-analytic survey was conducted through a questionnaire in digital format to measure consumer knowledge of commodity, specialty, and fermented coffees (Supplementary material). Participants were invited to participate in the survey via a hyperlink. The survey lasted approximately 5 minutes. All participants (1005) who agreed to take part in the survey were over 18 years old and were adequately informed about the study objectives. The survey was divided into three main sections. The first section aimed to correlate data on socio-demographic aspects-gender and age-with a frequency of coffee consumption. The questions of the second section aimed to uncover the behavior and perspectives of commodity and specialty coffee consumers, such as the characteristics observed when buying coffee, which flavors the commodity and specialty coffee consumers expect to find, besides preference, price, and others. The last section was directed toward fermented and inoculated coffees - to try to find out to try to find the reasons behind each consumers preference.

\subsection{Coffee processing}

Coffee cherries of the Catuaí Vermelho IAC-44 variety, grown at an altitude of $1200 \mathrm{~m}$ in the Caparaó region-Brazil, were fermented by a natural processing method (whole coffee fruit) for 72 hours in a closed polypropylene container, without adding water. Then, the cherries were transferred to suspended terraces until they obtained $11.5 \%$ moisture and stored under temperature-controlled conditions $\left(15^{\circ} \mathrm{C} \pm 2^{\circ} \mathrm{C}\right)$ until roasting.

The coffee beans were roasted according to the guidelines provided by the Specialty Coffee Association (Specialty Coffee Association, 2018) in a laboratory roaster (TP-2, Probat Leogap model, Curitiba, Brazil) for no longer than $24 \mathrm{~h}$ before tasting. The roasting lasted 9 minutes and 39 seconds, with a final temperature of $189^{\circ} \mathrm{C}$. The coffee beans were ground in an electric mill (Mahlkönig, EK43 model, Hamburg, Germany) before sensory analysis.

\subsection{Sensory analysis (Q-grader tasters and consumers)}

A sensory analysis was performed according to the SCA protocol (Specialty Coffee Association, 2018). Five cups from the same sample were used with a pre-determined ratio of $8.25 \pm 0.25 \mathrm{~g}$ per $150 \mathrm{~mL}$ of water $\left(92.2-94.4^{\circ} \mathrm{C}\right)$. During cupping, four expert coffee tasters with a Q-Grader Coffee Certificate evaluated fragrance, flavor, after taste, acidity, body, balance, uniformity, clean cup, sweetness, and overall impression following the assessment sheet of the SCA. They also described the flavor and sensory descriptors of coffee.

The acceptance test followed by the CATA test was performed with the participation of 101 consumers. The primary sensory descriptors described by expert coffee tasters were used for the CATA list. Thus, twelve descriptors were selected: chocolate, caramel, spice, mild flavor, milk, mint, almonds, sweet, citric, honey, fruity, and floral. The beverage preparation was at every 30 minutes, in a ratio of $80 \mathrm{~g}$ of ground coffee in $1 \mathrm{~L}$ of water. The samples were coded with three-digit numbers (Palermo, 2015 ) and were served monadically at a warm at a temperature of $60^{\circ} \mathrm{C}\left( \pm 1^{\circ} \mathrm{C}\right)$. The participants were instructed to rinse their mouths out with water between samples to clean their palates.

Sensory analysis was divided into two sessions and was performed at the Sensorial Analysis Laboratory of the Federal University of Lavras-UFLA (Lavras, MG-Brazil). In Session 1 (S1), the sample was served together with the sensory evaluation sheet without any information given to the consumers. The participants were invited to taste the sample and mark the sensory descriptors they perceived based on the CATA list. Besides, the hedonic scale of nine points (9-"extremely like" to 1- "extremely dislike") has been used to evaluate the flavor and global impression of the coffee. The same sample was served in Session 2 (S2) with the information, "This coffee is a specialty coffee, 85 points, obtained by spontaneous fermentation". The sensory evaluation sheet was the same as in the first session. This study (CAAE: 00147118.4.0000.5148) was reviewed and approved by the Ethics Committee of the Federal University of Lavras (UFLA), Lavras-MG, Brazil.

\subsection{Data analysis}

Statistical analyses were performed using the XLSTAT software. Survey data were evaluated by a k-proportions test, with a 5\% significance level and frequency responses. The frequency responses of the CATA test with consumers, the acceptance test with consumers, and the cupping with the Q-Graders were evaluated using a Cochran test, t-test, and Scott-Knott test, each with a $5 \%$ significance level. The correlation between the frequency of consumers' coffee consumption and the scores obtained for taste and the overall impression was evaluated by a principal component analysis (PCA).

\section{Results}

\subsection{Descriptive-analytic survey}

The characteristics of the participants and their frequencies of consumption are described in Table 1.

Over $77 \%$ of participants consume coffee daily, demonstrating that coffee is a product that is appreciated. The most common location for consumption remains the home, followed by work/university, and, lastly, coffee shops. Only 21 of 1005 participants answered that they do not consume the beverage. The majority of participants are from Brazil (98.2\%), and 1.8\% are from other countries.

The out of the total, $31.2 \%$ of participants, do not know what specialty coffee is. However, $91.2 \%$ of them said they would like to know more about specialty coffee, demonstrating receptivity to new sensory experiences. However, the knowledge about specialty coffees has increased from $68.8-72.7 \%$ after participants read a statement, "Special coffees are beans free of impurities and defects that have different sensory attributes, including clean and sweet, balanced body, acidity, and scores 80 or higher by a certified Q-Grader on the Specialty Coffee Association's quality scale. In addition to intrinsic quality, specialty coffees must have certified traceability and environmental, economic, and social 
sustainability criteria at all stages of production" (Associação Brasileira de Cafés Especiais, 2019), showing that there are gaps in communication between the market and consumer.

When asked why they would like to consume specialty coffees, the most cited reasons were: knowing/sensory experience and curiosity (51.1\%). Flavor and quality had $37.2 \%$ of the answers, while the aroma, pleasure, and sustainability represented $11.7 \%$.

More than half of participants (56.67\%) reported that they have difficulty finding specialty coffees or do not know places that sell these coffees. Besides, the price of specialty coffee influences the consumption of $21.46 \%$ of the participants. And, $80.4 \%$ of participants who consume specialty coffees are willing to pay up to approximately US \$ 6 for $250 \mathrm{~g}$ of coffee, pointing out that the price is not such a limiting factor.

Sales et al. (2020) reported that the Brazilian coffee consumers associated commodity coffee beans with higher quality compared to coffee powder and in capsules. Also, they correlated coffee beans with a more powerful aroma, flavor, and freshness, generating greater satisfaction and pleasure. The characteristics observed when buying commodity coffee and the reasons for consuming specialty coffees are the same. However, there is a difference in the priority of these characteristics (Figure 1). Flavor, aroma, and quality characteristics were the most mentioned. However,

Table 1. Population characteristics, according to coffee intake groups from questionnaire participants $(\mathrm{N}=1005)$.

\begin{tabular}{|c|c|c|c|c|c|}
\hline \multirow{2}{*}{ Parameters } & \multicolumn{4}{|c|}{ Frequency of coffee consumption } & \multirow{2}{*}{ Total $(\%$} \\
\hline & Never & 1-2 per week & 3-5 per week & Daily & \\
\hline \multicolumn{6}{|l|}{ Sex } \\
\hline Male & 6 & 34 & 47 & 377 & 46.17 \\
\hline Female & 15 & 63 & 58 & 405 & 53.83 \\
\hline \multicolumn{6}{|l|}{ Age (years) } \\
\hline $18-40$ & 19 & 79 & 80 & 496 & 67.07 \\
\hline $41-50$ & 0 & 9 & 15 & 105 & 12.83 \\
\hline$\geq 51$ & 2 & 9 & 10 & 181 & 20.1 \\
\hline \multicolumn{6}{|l|}{ Country } \\
\hline Brazil & 20 & 91 & 105 & 771 & 98.2 \\
\hline Other country ${ }^{1}$ & 1 & 6 & 1 & 10 & 1.8 \\
\hline \multicolumn{6}{|l|}{ Education } \\
\hline High school $^{2}$ & 0 & 9 & 0 & 65 & 7.37 \\
\hline Undergraduate $^{2}$ & 10 & 51 & 50 & 316 & 42.5 \\
\hline Postgraduate & 11 & 37 & 55 & 401 & 50.13 \\
\hline \multicolumn{6}{|l|}{ Consumption $^{3 *}$} \\
\hline Home & - & 69 & 82 & 720 & - \\
\hline Work/University & - & 42 & 68 & 526 & - \\
\hline Coffee shop & - & 27 & 33 & 346 & - \\
\hline
\end{tabular}

${ }^{1}$ Countries: Argentina, Colombia, China, Guatemala, United States, London, Nepal, United Arab Emirates, Venezuela; ${ }^{2}$ Studying/complete; ${ }^{3}$ Local of consumption; ${ }^{*}$ May have more than one answer.

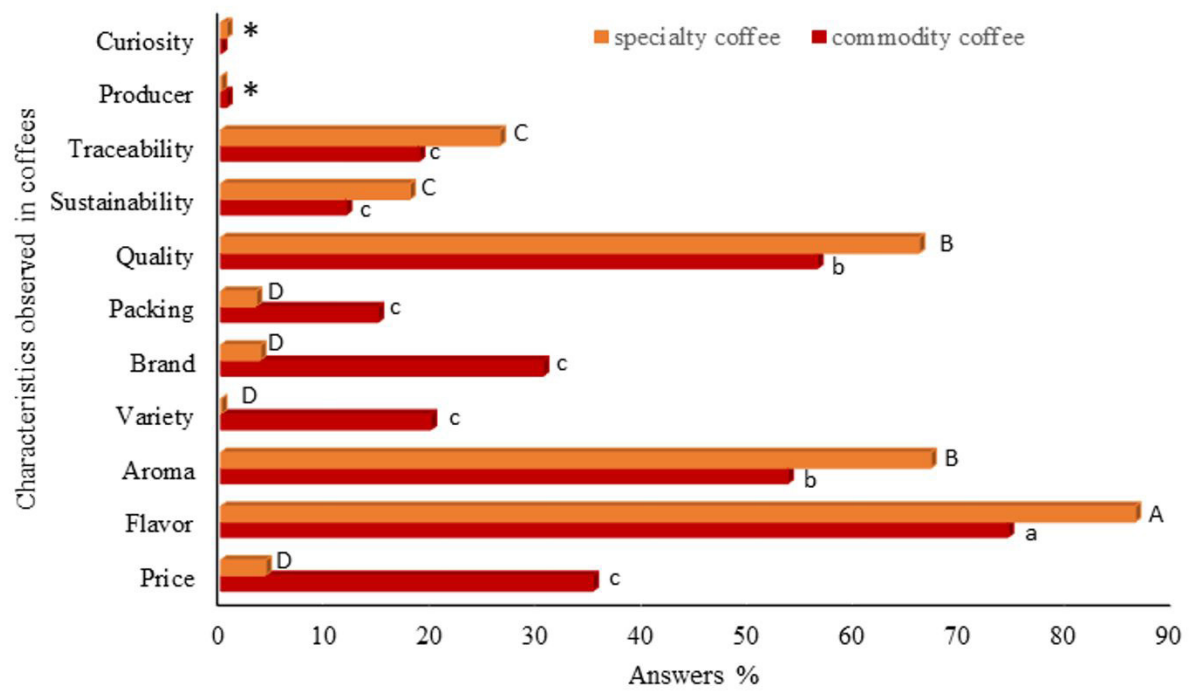

Figure 1. Characteristics observed by respondents when buying coffee. Different lowercase letters show a statistical difference at $\mathrm{p}<0.05$ by k-proportions test between the characteristics observed when buying commodity coffee. Different capital letters show statistical difference at $\mathrm{p}<0.05$ by k-proportions test between the characteristics observed when buying specialty coffee. ${ }^{\star}$ There was no statistical difference at $\mathrm{p}<0.05$ by k-proportions test in each characteristic observed between commodity and specialty coffee. 
mentions of these factors increase, on average, $12 \%$ when talking about the consumption of specialty coffees, and become essential. This increase also has been observed in traceability and sustainability. In contrast, the price, variety, brand, and packing decreased in importance when buying specialty coffees-up to a $30 \%$ difference compared to commodity coffees (for price and brand). Curiosity about the producer showed no significant difference between commodity and specialty coffee (Figure 1).

Flavor (86.3\%) was the most-cited attribute for specialty coffee, significantly more frequently than the others. Aroma (62.2\%) and aftertaste (56.1\%) were also highly cited but did not show a significant difference amongst themselves. The leastconsidered attributes were the degree of roasting $(29.4 \%)$ and body (31.6\%)- there was no significant difference between them. Chocolate is the flavor that consumers most expect to find in specialty coffees (presenting a significant difference). Caramel, fruit, and nuts and almonds were also frequently cited

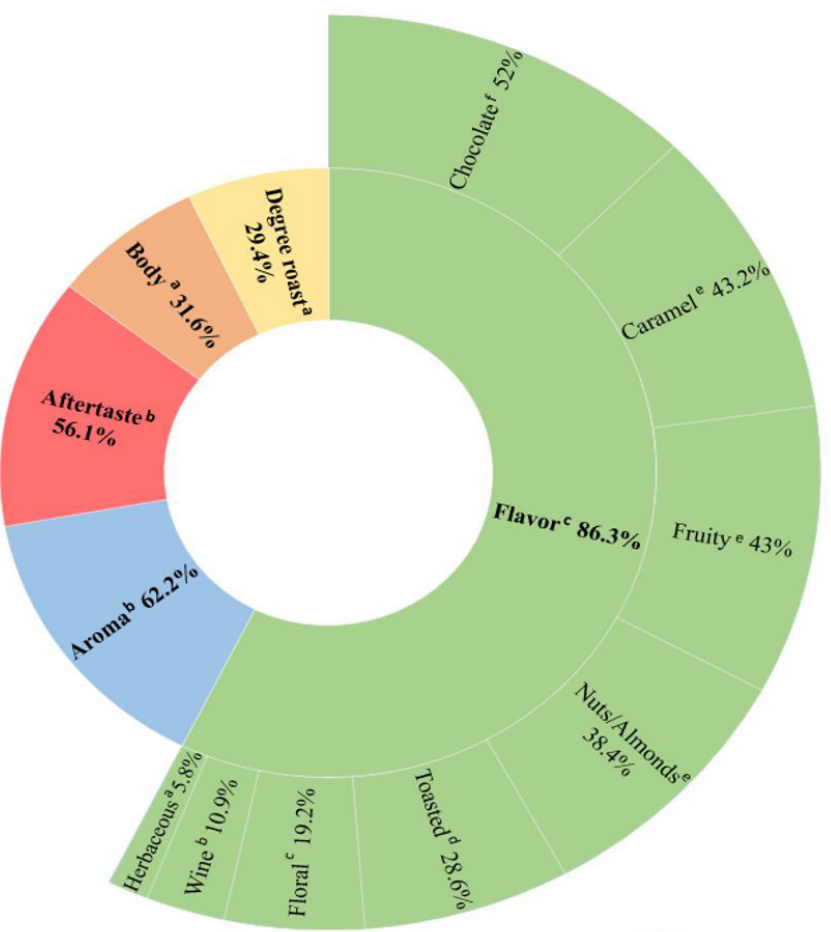

Figure 2. Important attributes evaluated when consuming specialty coffee and flavors that respondents expect to find in a specialty coffee. Different bold lowercase letters show a statistical difference at $\mathrm{p}<0.05$ by k-proportions test between the following characteristics: flavor, aroma, aftertaste, body, and degree of roast characteristics-different lowercase letters without bold show statistical difference at $\mathrm{p}<0.05$ by k-proportions test between flavors. and showed no significant difference amongst them. Further, $28.6 \%$ of the participants expected the coffee to have a roasted flavor (Figure 2).

Of the five basic tastes, sweet is what consumers expect most (71.4\%). Bitter is the second basic taste they expect to find in specialty coffee $(41.6 \%)$, even though this type of coffee has a lower bitterness compared to commodity coffee.

The last part of the questionnaire focuses on fermented coffees. $48.5 \%$ of participants did not know that coffee can undergo a controlled fermentation process, and only $28.6 \%$ had ever consumed this type of coffee. This result shows that, despite the growth of specialty coffees, information about fermented coffee needs to be spread to consumers since $89.6 \%$ of participants would like to consume this type of coffee, mainly for the best taste.

According to the survey, only $36.7 \%$ of participants knew about fermented coffee with microorganism starters. Only $16.2 \%$ had consumed this type of coffee, and the main attributes of coffee inoculated with microorganisms that pleased the interviewees were flavor (most cited: chocolate (51\%), caramel (24\%), floral (7\%), fruity (6\%), red fruits (5\%), and wine $(5 \%)$ ), aroma, being different/exotic, and acidity. Besides, the acceptance rate of participants who have not tasted fermented coffees is much higher when the known inoculum (90.5\%) than when the inoculum is unknown (46.1\%).

\subsection{Sensory analysis}

Four trained tasters evaluated the fermented coffee sample according to the SCA protocol. The coffee received an average score of 85.15 (Table 2), and the most cited sensory characteristics of flavor were: chocolate, caramel, almonds, spices, soft flavor, milk, mint, citric, fruity, honey, sweet, and floral. The score was used in the information presented to consumers in the second session of the sensory analysis to verify its influence on the acceptance test and the sensory characteristics perceived in the CATA test.

The panel of 101 untrained consumers was composed of 62 females and 39 males, aged 18-60 years. Almost 47\% of the participants drink coffee with sugar, and of these, $57 \%$ are women. Also, $75 \%$ of tasters drink coffee daily.

Acceptance was classified between "moderately like" and "very much like" (7.0-7.1 and 7.0-7.2, respectively) according to the hedonic scale (in the acceptance test) of taste and overall impression (in Sessions 1 and 2).

The PCA analysis (Figure 3) allowed the correlation between the frequency of coffee consumption by participants and the scores obtained for taste and overall impression. The information

Table 2. The total score of each expert taster for coffee beverages (scale Specialty Coffee Association, 2018).

\begin{tabular}{ccccc}
\hline & \multicolumn{3}{c}{ Expert coffee tasters } \\
\cline { 2 - 4 } & T1 & T2 & T3 \\
\hline Final score & $85.08^{\mathrm{a}} \pm 0.88$ & $85.17^{\mathrm{a}} \pm 0.52$ & $85.08^{\mathrm{a}} \pm 1.18$ & $85.25^{\mathrm{a}} \pm 1.25$ \\
\hline $\begin{array}{l}\mathrm{MV}=\text { mean value of all tasters. Mean values } \pm \text { standard deviation within the same lowercase superscript letters no differ significantly }(p<0.05) \\
\text { grades of each Q-Grader taster. All analyses were carried out in triplicate. }\end{array}$
\end{tabular}


(A1)

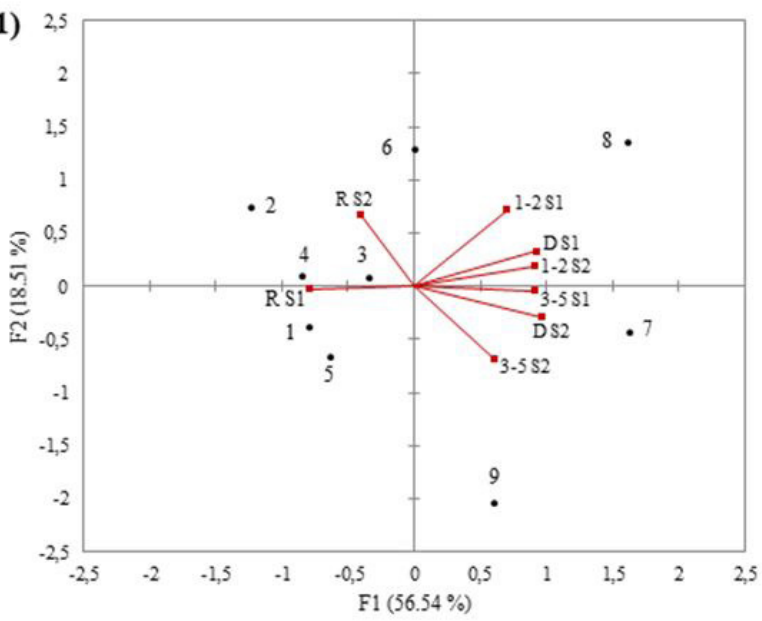

(B1)

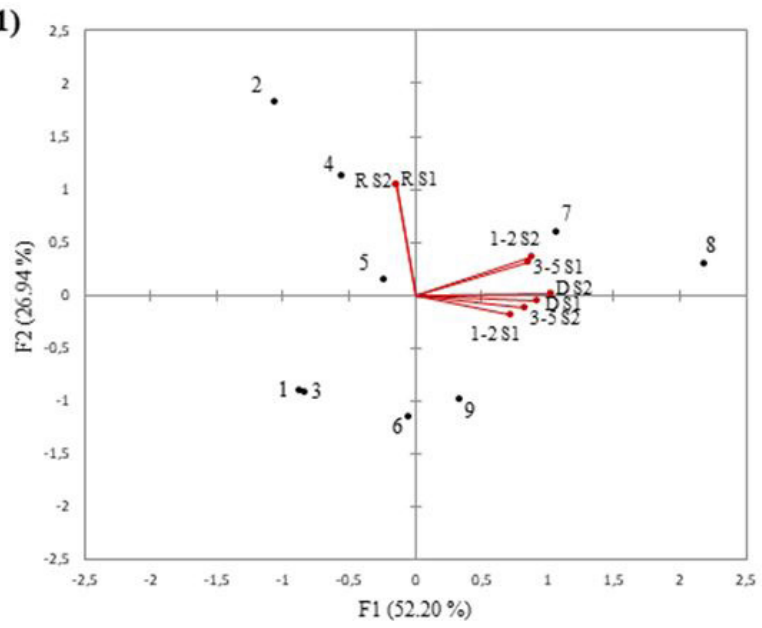

(A2)

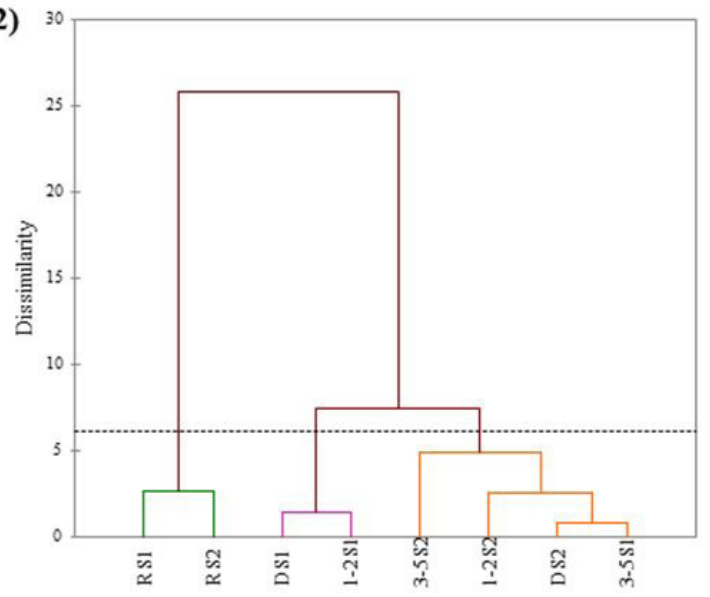

(B2)

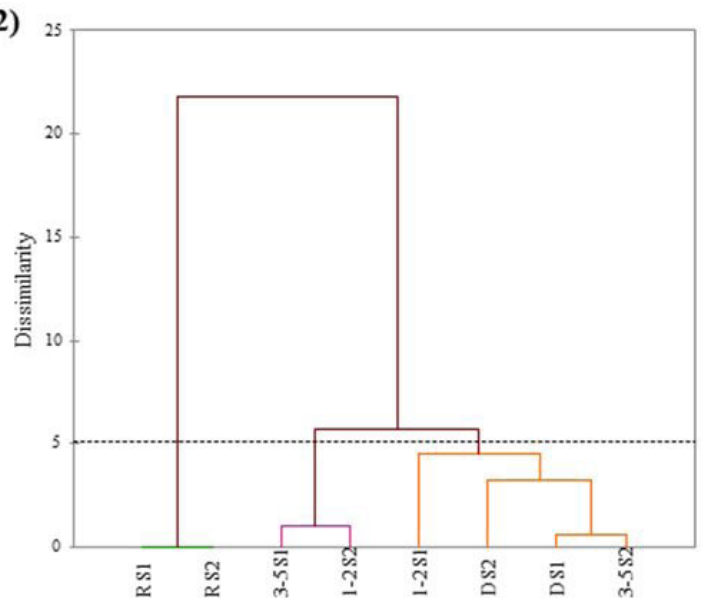

Figure 3. Correlation between the frequency of coffee consumption by consumers and the scores obtained for taste and overall impression were evaluated by principal component analysis (PCA) and cluster through dendrogram. A = Score evaluated for flavor; $\mathrm{B}=\mathrm{Score}$ evaluated for global impression. Frequency of coffee consumption: $\mathrm{D}=$ Daily; $3-5=3$ to 5 times a week; $1-2=1$ to 2 times a week; $\mathrm{R}=\mathrm{Rarely}$; $\mathrm{S} 1=\mathrm{Session} 1$ and S2 = Session 2. (-) Frequency of coffee consumption in each session.

less influenced the tasters who consume coffee rarely $(\mathrm{R})$. Those tasters were characterized by lower scores for flavor (between 3 and 4). The same happened with tasters who drink coffee 1-2 times a week; however, they scored the coffee higher, at 8 . Although the group of tasters who consume coffee 3-5 days a week are in the same quadrant in S1 and S2, it can be observed that the information had a significant influence on the taste score. In S1, this group was characterized by a score of 7 , while in S2, the score was closer to 9. Unlike expected, the information had a negative effect on the taste score of the tasters who drink coffee daily (D) (S1 was characterized by a score of 8 , and S2 by a score of 7) (Figure 3A1). Thus, the cluster analysis separated consumers into three main groups. Only those who consumed coffee rarely $(\mathrm{R})$ had the same grouping in S1 and S2 (Figure 3A2).

In Figure 3B1, it can be observed that $79.14 \%$ of the total variance for the global impression scores were explained. Again, the tasters who consume coffee rarely $(\mathrm{R})$ were characterized by the same score (4) in both S1 and S2. In this case, the information negatively influenced the scores of those who consumed coffee 1-2 times a week -in S1. S1 group was closer to a score of 9, and in S2, a score of 7. The tasters who drink coffee 3-5 times a week were also influenced by the information and had the highest overall impression score in S2 (closer to a score of 9). Tasters who drink coffee daily (D) did not seem to be influenced by the information and were characterized by a score of 8 in both sessions (Figure 3B1).

As for taste, Figure 3B2 shows that those who rarely consumed coffee were in the same group for both sessions. Those who drink coffee 3-5 times a week in S2 and those who drink coffee 1-2 times a week in $\mathrm{S} 1$ are in the same group, most closely related by a higher score. A dissimilarity of Groups 5-3 can be observed in Figure 3B2.

In S1, participants perceived sweeter and more caramel descriptors. After the information (S2) that the coffee scored 85 points and was fermented, the perception changed, and participants described the coffee as more citric and fruity. The perception of honey and floral descriptors showed no difference between S1 and S2 (Figure 4). These results indicate that untrained consumers perceived some attributes described by Q-Graders. However, they could be influenced by the information provided. 


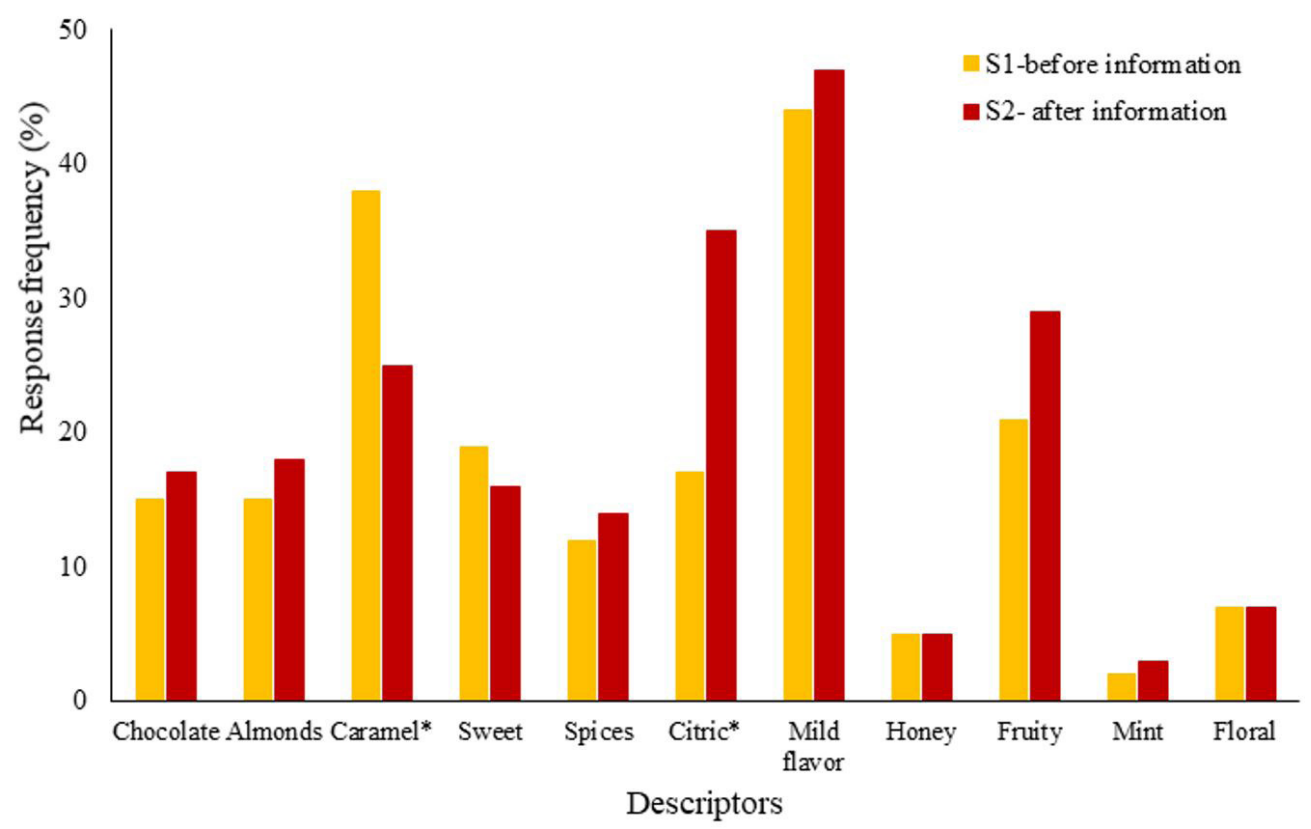

Figure 4. The frequency response of the CATA test with consumers before and after information provided to tasters. The sensory descriptors with ${ }^{*}$ show statistical difference at $\mathrm{p}<0.05$ by the Cochran test from the same sample before and after the information.

\section{Discussion}

The survey aimed to understand the knowledge and perspectives of consumers about commodity, specialty, and fermented coffees. Brazil is still the largest producer and exporter of coffee in the world. According to the Empresa Brasileira de Pesquisa Agropecuária (2019), every year, the world consumption of the beverage grows around 1.5\%. In particular, Brazilians are drinking more coffee (second-largest consumer of the beverage), and consumption is projected to increase by 3.5\%, confirming a positive projection for coffee growers. Therefore, the expectations and desires of consumers must be considered, reaching a broader market (Wang \& Yu, 2016).

The third wave of coffee is based on the differentiation and experience of consuming this complex beverage (Boaventura et al., 2018; Guimarães et al., 2019). The interest of participants in trying specialty coffees indicates a growth trend for this market, with higher availability and approximation of consumers. More than quality, consumers want to service and experiences to be pleasant (Sousa et al., 2016; Wang \& Yu, 2016; Ufer et al., 2019).

Despite the interest of consumers, price is one of the factors that influence their purchase decision, and promotions can stimulate increased sales (Samoggia \& Riedel, 2018).

Coffee aroma and flavor are the most important properties determining consumers' preference and acceptance (Bressanello et al., 2018; Wang et al., 2019). Customers place significant value on coffee shops that provide sensory experiences, unique coffee flavors, and consistent quality (Kim \& Lee, 2017). And as consumers become more demanding and aware (Ratton \& Spers, 2020), they are more concerned with knowing the characteristics and information of the products they consume. Consequently, producers tend to change their postharvest processes to meet the demands. Thus, the controlled fermentation process aims to assist in improving the quality of specialty coffees, diversifying the flavor and aroma of the beverage (Evangelista et al., 2014; Bressani et al., 2018, 2020; Haile \& Kang, 2019; Wang et al., 2019).

There are no studies that meet consumer expectations regarding flavor descriptors. In this work, it was found that chocolate is the flavor that consumers most expect to find in specialty coffees, followed by caramel, fruit, and nuts, and almonds. However, many consumers still have the habit of coffee with excessive roasting (commodity), which may explain why $28.6 \%$ of the participants expected the coffee to have a roasted flavor. According to Monteiro (Monteiro et al., 2010), consumers preferred the most darkly roasted coffees, regardless of the type of beverage. On the other hand, Giacalone et al. (2019) showed that consumers preferred coffees with regular roasting. According to the degree of roasting, the composition of some chemical compounds can be variable because there is partial degradation of phenolic compounds and the development of aromatic and bioactive compounds (Cruz et al., 2017).

The human being has always looked for the sweet taste, which is significantly related to pleasure and reward (Almeida, 2017). As expected, the sweet taste is what consumers most expect to find in coffee. Despite being considered an attribute negative in some foods (Varela et al., 2014), many consumers appreciate a certain amount of bitterness in products such as coffee, beer, or dark chocolate. In a study by Giacalone et al. (Giacalone et al., 2019), the consumers strongly correlate bitterness with darker roasting.

Research has shown that consumers are more demanding and willing to try different products. Even though they can recognize the quality of the beverage, they still have limited 
perception to describe the sensory characteristics. Therefore, the sensory evaluation performed by trained Q-Grader tasters is essential because it helps establish the purchase and sale value of specialty coffees through their score based on SCA protocol and the perceptions of sensory descriptors (Conley \& Wilson, 2020). However, it is also important to know the behavior regarding preferences, intentions, and desires.

The average scores of flavor and overall impression in S1 and S2 did not differ significantly. However, a slight increase can be seen after adding the information, showing an influence on the acceptability and perception of sensory characteristics of the coffee. Overall, the coffee had reasonable rates of sensory acceptance for both flavor and overall impression. The information influences the sensory perceptions and responses because it creates expectations (Spence, 2015; Spence \& Carvalho, 2020). Consumers who drink coffee more often showed high expectations for sensory analysis. In the same sense, the perception of the sensory descriptors was different for the two sessions. Despite having been served with the same coffee in both sessions, most tasters correlate the specialty/fermented coffee with citric and fruity descriptors. These results indicate that untrained consumers perceived some attributes described by the Q-Graders. However, they could be influenced by the information provided due to expectations about specialty/fermented coffees.

\section{Conclusions}

Descriptive-analytical research clearly showed how consumers understand specialty coffees and their perspectives on the beverage. In general, the participants knew little about specialty/fermented coffee but were willing to try different coffees. Chocolate is the flavor that consumers most expect to find in specialty coffee. These results are important, as they can help practitioners both know better the trend of the market and adjust the position of products or services more assertively.

Sensorially, the coffee had a good acceptance. The information mainly positively influenced the group who drink coffee 3-5 times a week. The caramel and citric descriptor showed a significant difference between $\mathrm{S} 1$ and $\mathrm{S} 2$, the citric descriptor being the most related to fermented coffees (after information). Consumers' expectations can be influenced by information, modifying their sensory perception.

\section{Acknowledgements}

This work was supported by the Conselho Nacional de Desenvolvimento Científico e Tecnológico of Brasil (CNPq), Fundação de Amparo à Pesquisa do Estado de Minas Gerais (FAPEMIG), and Coordenação de Aperfeiçoamento de Pessoal de Nível Superior (CAPES). The authors would like to thank Caparaó Jr. for analyzing cup tasting with trained tasters and coffee producers from Caparaó for collecting the samples.

\section{References}

Alcantara, M., \& Freitas-Sá, D. G. C. (2018). Rapid and versatile sensory descriptive methods - An updating of sensory science. Brazilian Journal of Food Technology, 21, e2016179. http://dx.doi. org/10.1590/1981-6723.17916.
Almeida, M. G. (2017). Beyond beliefs about food and the flavors of nature. Mercator (Fortaleza), 16, 1-13. http://dx.doi.org/10.4215/ rm2017.e16006.

Associação Brasileira de Cafés Especiais - BSCA (2019). Retrieved from https://bsca.com.br/a-bsca\#: :text=O\%20que\%20\%C3\%A9\%20 cafe\%20especial,80\%20pontos\%20na\%20an\%C3\%A1lise\%20sensorial.

Boaventura, P., Abdalla, C., Araújo, C., \& Arakelian, J. (2018). Cocriação de valor na cadeia do café especial: o movimento da terceira onda do café. Revista de Administração de Empresas, 58(3), 254-266. http:// dx.doi.org/10.1590/s0034-759020180306.

Bressanello, D., Liberto, E., Cordero, C., Sgorbini, B., Rubiolo, P., Pellegrino, G., Ruosi, M. R., \& Bicchi, C. (2018). Chemometric modeling of coffee sensory notes through their chemical signatures: potential and limits in defining an analytical tool for quality control. Journal of Agricultural and Food Chemistry, 66(27), 7096-7109. http://dx.doi. org/10.1021/acs.jafc.8b01340. PMid:29895143.

Bressani, A. P. P., Martinez, S. J., Evangelista, S. R., Dias, D. R., \& Schwan, R. F. (2018). Characteristics of fermented coffee inoculated with yeast starter cultures using different inoculation methods. Lebensmittel-Wissenschaft + Technologie, 92, 212-219. http://dx.doi. org/10.1016/j.lwt.2018.02.029.

Bressani, A. P. P., Martinez, S. J., Sarmento, A. B. I., Borém, F. M., \& Schwan, R. F. (2020). Organic acids produced during fermentation and sensory perception in specialty coffee using yeast starter culture. Food Research International, 128, 108773. http://dx.doi.org/10.1016/j. foodres.2019.108773. PMid:31955746.

Carvalho, N. B., Minim, V. P. R., Nascimento, M., Vidigal, M. C. T. R., Ferreira, M. A. M., Gonçalves, A. C. A., \& Minim, L. A. (2015). A discriminant function for validation of the cluster analysis and behavioral prediction of the coffee market. Food Research International, 77, 400-407. http://dx.doi.org/10.1016/j.foodres.2015.10.013.

Conley, J., \& Wilson, B. (2020). Coffee terroir: cupping description profiles and their impact upon prices in Central American coffees. GeoJournal, 85(1), 67-79. http://dx.doi.org/10.1007/s10708-018-9949-1.

Costa, G. M., Paula, M. M., Costa, G. N., Esmerino, E. A., Silva, R., De Freitas, M. Q., Barão, C. E., Cruz, A. G., \& Pimentel, T. C. (2020). Preferred attribute elicitation methodology compared to conventional descriptive analysis: a study using probiotic yogurt sweetened with xylitol and added with prebiotic components. Journal of Sensory Studies, 35(6), e12602. http://dx.doi.org/10.1111/joss.12602.

Cruz, R. G., Vieira, T. M. F. S., \& Lira, S. P. (2017). Potential antioxidant of Brazilian coffee from the region of cerrado. Food Science and Technology, 38(3), 447-453. http://dx.doi.org/10.1590/1678-457x.08017.

Empresa Brasileira de Pesquisa Agropecuária - Embrapa. (2019). Consumo interno dos cafés do Brasil representa 13\% da demanda mundial. Retrieved from http://www.consorciopesquisacafe.com. br/index.php/imprensa/noticias/909-2019-02-12-13-16-41

Evangelista, S. R., Silva, C. F., Miguel, M. G. P. da C., Cordeiro, C. de S., Pinheiro, A. C. M., Duarte, W. F., \& Schwan, R. F. (2014). Improvement of coffee beverage quality by using selected yeasts strains during the fermentation in dry process. Food Research International, 61, 183-195. http://dx.doi.org/10.1016/j.foodres.2013.11.033.

Giacalone, D., Degn, T. K., Yang, N., Liu, C., Fisk, I., \& Münchow, M. (2019). Common roasting defects in coffee: aroma composition, sensory characterization and consumer perception. Food Quality and Preference, 71, 463-474. http://dx.doi.org/10.1016/j.foodqual.2018.03.009.

Giacalone, D., Fosgaard, T. R., Steen, I., \& Münchow, M. (2016). "Quality does not sell itself": divergence between "objective" product quality and preference for coffee in naïve consumers. British Food Journal, 118(10), 2462-2474. http://dx.doi.org/10.1108/BFJ-03-2016-0127. 
Guimarães, E. R., Leme, P. H. M. V., Rezende, D. C., Pereira, S. P., \& Santos, A. C. (2019). The brand new Brazilian specialty coffee market. Journal of Food Products Marketing, 25(1), 49-71. http:// dx.doi.org/10.1080/10454446.2018.1478757.

Haile, M., \& Kang, W. H. (2019). The role of microbes in coffee fermentation and their impact on coffee quality. Journal of Food Quality, 2019, 1-6. http://dx.doi.org/10.1155/2019/4836709.

Kim, S. H., \& Lee, S. (2017). Promoting customers' involvement with service brands: evidence from coffee shop customers. Journal of Services Marketing, 31(7), 733-744. http://dx.doi.org/10.1108/ JSM-03-2016-0133.

Li, J., Streletskaya, N. A., \& Gómez, M. I. (2019). Does taste sensitivity matter? The effect of coffee sensory tasting information and taste sensitivity on consumer preferences. Food Quality and Preference, 71, 447-451. http://dx.doi.org/10.1016/j.foodqual.2018.08.006.

Monteiro, M. A. M., Minim, V. P. R., Silva, A. F., \& Chaves, J. B. P. (2010). Influência da torra sobre a aceitação da bebida café. Revista Ceres, 57(2), 145-150. http://dx.doi.org/10.1590/S0034-737X2010000200002.

Palermo, J. R. (2015). Métodos para avaliação sensorial. In J. R. Palermo (Ed.), Análise sensorial: fundamentos e métodos (1. ed., pp. 57-111). Rio de Janeiro: Atheneu.

Ratton, J. O. M., \& Spers, E. E. (2020). Certifications for coffee cultivation: characterizing personal values of producers and consumers. In L. F. Almeida \& E. E. Spers (Eds.), Coffee consumption and industry strategies in Brazil (pp. 93-108). Oxford: Woodhead Publishing. . http://dx.doi.org/10.1016/B978-0-12-814721-4.00004-4.

Sales, Y. J. D., Corrêa, F. J. B., Tavares-Filho, E. R., Soares, P. T. S., Durço, B. B., Pagani, M. M., Freitas, M. Q., Cruz, A. G., \& Esmerino, E. A. (2020). Insights of Brazilian consumers' behavior for different coffee presentations: an exploratory study comparing hard laddering and completion task. Journal of Sensory Studies, 35(6), e12611. http:// dx.doi.org/10.1111/joss.12611.

Samoggia, A., \& Riedel, B. (2018). Coffee consumption and purchasing behavior review: insights for further research. Appetite, 129, 70-81. http://dx.doi.org/10.1016/j.appet.2018.07.002. PMid:29991442.

Samoggia, A., \& Riedel, B. (2019). Consumers' perceptions of coffee health benefits and motives for coffee consumption and purchasing. Nutrients, 11(3), 653. http://dx.doi.org/10.3390/nu11030653. PMid:30889887.

Sass, C. A. B., Pimentel, T. C., Aleixo, M. G. B., Dantas, T. M., Oliveira, F. L. C., Freitas, M. Q., Cruz, A. G., \& Esmerino, E. A. (2020). Exploring social media data to understand consumers' perception of eggs: a multilingual study using Twitter. Journal of Sensory Studies, 35(6), e12607. http://dx.doi.org/10.1111/joss.12607.

Schuch, A. F., Silva, A. C., Kalschne, D. L., Silva-Buzanello, R. A., Corso, M. P., \& Canan, C. (2019). Chicken nuggets packaging attributes impact on consumer purchase intention. Food Science and Technology (Campinas), 39(Suppl. 1upl. Suppl. 1), 152-158. http://dx.doi.org/10.1590/fst.41317.
Silva, H. L. A., Balthazar, C. F., Silva, R., Vieira, A. H., Costa, R. G. B., Esmerino, E. A., Freitas, M. Q., \& Cruz, A. G. (2018). Sodium reduction and flavor enhancer addition in probiotic prato cheese: Contributions of quantitative descriptive analysis and temporal dominance of sensations for sensory profiling. Journal of Dairy Science, 101(10), 8837-8846. http://dx.doi.org/10.3168/jds.201814819. PMid:30077456.

Sousa, A. G., Machado, L. M. M., Silva, E. F., \& Costa, T. H. M. (2016). Personal characteristics of coffee consumers and non-consumers, reasons and preferences for foods eaten with coffee among adults from the Federal District, Brazil. Food Science and Technology (Campinas), 36(3), 432-438. http://dx.doi.org/10.1590/1678-457X.10015.

Specialty Coffee Association. (2018). Coffee standards: table of contents (p. 14). California. Retrieved from https://static1.squarespace. com/static/584f6bbef5e23149e5522201/t/5bd985c1352f53cb4cc1 be48/1540982325719/Coffee+Standards-Digital.pdf

Spence, C. (2015). Multisensory flavor perception. Cell, 161(1), 24-35. http://dx.doi.org/10.1016/j.cell.2015.03.007. PMid:25815982.

Spence, C., \& Carvalho, F. M. (2020). The coffee drinking experience: Product extrinsic (atmospheric) influences on taste and choice. Food Quality and Preference, 80, 103802. http://dx.doi.org/10.1016/j. foodqual.2019.103802.

Torres, F. R., Silva, H. L. A., Cutrim, C. S., \& Cortez, M. A. S. (2020). Consumer perception of Petit-Suisse cheese: identifying market opportunities for the Brazilian dairy industry. Food Science and Technology, 40(Suppl. 2), 653-660. http://dx.doi.org/10.1590/fst.38319.

Ufer, D., Lin, W., \& Ortega, D. L. (2019). Personality traits and preferences for specialty coffee: Results from a coffee shop field experiment. Food Quality and Preference, 125, 125. PMid:31554119.

Varela, P., Beltrán, J., \& Fiszman, S. (2014). An alternative way to uncover drivers of coffee liking: preference mapping based on consumers' preference ranking and open comments. Food Quality and Preference, 32, 152-159. http://dx.doi.org/10.1016/j.foodqual.2013.03.004.

Vieira, A. H., Balthazar, C. F., Rocha, R. S., Silva, R., Guimaraes, J. T., Pagani, M. M., Pimentel, T. C., Esmerino, E. A., Silva, M. C., Tonon, R. V., Cabral, L. M., Freitas, M. Q., \& Cruz, A. G. (2020). The free listing task for describing the sensory profiling of dairy foods: a case study with microfiltered goat whey orange juice beverage. Journal of Sensory Studies, 35(5), e12594. http://dx.doi.org/10.1111/joss.12594.

Wang, C., Sun, J., Lassabliere, B., Yu, B., Zhao, F., Zhao, F., Chen, Y., \& Liu, S. Q. (2019). Potential of lactic acid bacteria to modulate coffee volatiles and effect of glucose supplementation: fermentation of green coffee beans and impact of coffee roasting. Journal of the Science of Food and Agriculture, 99(1), 409-420. http://dx.doi.org/10.1002/ jsfa.9202. PMid:29896755.

Wang, E. S. T., \& Yu, J. R. (2016). Effect of product attribute beliefs of ready-to-drink coffee beverages on consumer-perceived value and repurchase intention. British Food Journal, 118(12), 2963-2980. http://dx.doi.org/10.1108/BFJ-03-2016-0128. 
Bressani et al.

\section{Supplementary material}

Supplementary material accompanies this paper.

Legend S1. Questionnaire: Study on consumer perception of commodity, specialty and fermented coffees.

Legend S1. Sensory Assessment Sheet with consumers.

This material is available as part of the online article from http://www.scielo.br/CTA 